\title{
Simulation of Seasonal Cloud Forcing Anomalies
}

DOE/ER/69027--T2

\author{
David A. Randall
}

DE92 018778
Department of Atmospheric Science
Colorado State University
Fort Collins, Colorado 80523

FGO2-89ER69027

Paper Presented at the

Joint U.S. - Indian Seminar on Parameterization for Large-Scale Models

August 1990

\section{DISCLAIMER}

\begin{abstract}
This report was ptepared as an account of work sponsored by an agency of the United States Government. Neither the United States Gnvernment nor any agency thereof, nor any of their employees, makes any wartanly, express or implied, or assumes any legal liability or responsibility for the eccuracy, completeness, or usefulness of any information, apparatus, product, or process disclosed, or represents that its use would not infringe privately owned rights. Reference herein to any specific commercial product, process, or service by trade name, trademark, manufucturer, or otherwise does not nocessarily constitute or imply its endoreement, racommendation, of favoring by the Unitod States Government or any agency theroof. The views and opinions of author expressed herein do not necussarily state or refloct those of the Unitod States Government of any agency thereor.
\end{abstract}

\section{MASTER}




\section{Introduction}

One useful way to classify clouds is according to the processes that generate them. There are three main cloud-formation agencies:

1) a?

- deep convection, which produces stratiform cloud shields that are much more extensive than the convective elements themselves;

- surface evaporation, which can maintain thin but radiatively important stratiform cloud sheets in the boundary layer, as well as broken fields of shallow convective clouds that occur with great frequency; and

- large-scale lifting in the absence of conditional instability, which can generate extensive stratiform cloud decks in the free atmosphere.

The third of these, the "stable large-scale lifting" mechanism, is the one emphasized in older textbooks, but is probably the least important. Some modern general circulation models attempt to include all three of these cloud types.

Although traditionally clouds have been viewed as influencing the atmospheric general circulation primarily through the release of latent heat, the atmospheric science literature contains abundant evidence that, in reality, clouds influence the general circulation through four more or less equally important effects:

- interactions with the solar and terrestrial radiation fields, which are now known to have a net cooling effect on the Earth, but exert unknown feedbacks on climate change processes;

- condensation and evaporation, which modify the density of the air,

- precipitation, which transports liquid water and ice downward and ultimately removes them from the atmosphere; and

- small-scale circulations within the atmosphere, which produce vertical fluxes of moisture, sensible heat, and momenturn, as well as various chemical constituents.

The most advanced of the current generation of GCMs include parameterizations of all four effects.

Until recently there has been lin outing skepticism, in the general circulation modeling community, that the radiative effects of clouds significantly influence the atmospheric general circulation. Zonally uniform "observed" cloud amounts were, in some cases, prescribed by modelers who preferred to avoid confronting the complex physics of cloud formation. Ironically, GCMs have provided the proof that the radiative effects of clouds are important for the general circulation of the atmosphere (Ramanathan et al., 1983; Slingo and Slingo, 1988; Randall et al., 1989).

An important concept in analysis of the effects of clouds on climate is the cloud radiative forcing (CRF), which is defined as the difference between the radiative flux (at the top of the atmosphere, say) which actually occurs in the presence of clouds, and that which would occur if the clouds were removed but the atmospheric state were otherwise unchanged (Ellis, 1978; Charlock and Ramanathan, 1985). We also use the term CRF to denote warming or cooling tendencies due to cloud-radiation interactions. Cloud feedback is the change in CRF that accompanies a climate change. 
It is useful to distinguish among three aspects of the CRF: the "planetary CRF" acting at the top of the atmosphere, the "surface CRF" at the Earth's surface, and the "atmospheric CRF," which acts on the atmosphere itself and is the difference between the planetary and surface CRFs. The planetary CRF, which can be observed from satellites, can be thought of as the sum of the surface CRF and the atmospheric CRF. Because clouds do not absorb much solar radiation, the atmospheric CRF (hereafter, ACRF) is mostly due to the emission and absorption of infrared radiation by clouds. The surface CRF involves important contributions from both solar and infrared radiation.

The present study concentrates on the planetary CRF and its response to external forcing, i.e. seasonal change.

\section{Recent studies of the effects of clouds on the atmospheric general circulation}

Cox discussed the radiative heating and cooling profiles associated with various cloud types, and showed that upper-tropospheric clouds lead to a warming of the atmospheric column. Albrecht and Cox (1975), Stephens and Webster, (1979), Webster and Stephens (1980), and Ackerman et al. (1988) presented evidence that the radiative effects of tropical upper-tropospheric clouds can be cornparable in magnitude to the latent heating associated with the formation of the clouds. These inferences have recently been confirmed and extended by studies with climate models.

Slingo and Slingo (1988) performed an experiment with the Community Climate Model (CCM) maintained by the National Center for Atmospheric Research, in which the longwave atmospheric cloud radiative forcing (hereafter, ACRF) was artificially suppressed. Clear-sky cooling rates were used to predict the atmospheric temperature, while the usual (clear and cloudy) longwave flux was used to predict the land-surface temperature. January conditions were chosen on the grounds that the land-surface is minimally sensitive to longwave ACRF in northem winter. A partial summary of their results is as follows: the ACRF warms the tropical upper troposphere by $4 \mathrm{~K}$ and cools the tropical lower stratosphere by $6 \mathrm{~K}$, causing an acceleration of the subtropical jets in both hemispheres. It produces a moistening of the tropical middle troposphere by invigorating moist convection, which transports moisture upwards. It causes increased precipitation and large-scale rising motion over Indonesia, and tends to increase the rate of precipitation in regions where precipitation is likely to occur anyway.

Randall et al. (1989) performed an analogous experiment with the Colorado State University (CSU) GCM (formerly the UCLAVGLA FCM) to determine to what extent the CCMbased results of Slingo and Slingo are model-dependent. A description of the CSU model is omitted here for brevity, but can be found in the reference just mentioned. Suffice it to say that the CCM and the CSU GCM are very different. Nevertheless, the CSU GCM gives results qualitatively similar to those produced by the CCM. In particular, both models suggest that the ACRF acts to increase the precipitation rate over the tropical octeans.

To explore the reasons for this, Randall et al. (1989) performed numerical simulations of the atmospheric general circulation of an ocean-covered planet, with and without the radiative effects of clouds. They fcund that by radiatively warming convectively active columns, the ACRF strengthens the large-scale rising motion, the low-level convergence, and the surface evaporation, leading to more convective cloudiness and a further warming of the column. This positive feedback mechanism operates very effectively over the oceans, where the simulated sea surface temperature is either slowly varying (in the real world and in coupled ocean-atmosphere models) or fixed (in models of the atmosphere alone). As shown in Fig. 5, they found that the ACRF can actually double the strength of the Hadley circulation on an ocean-covered planet called "Sezworld." 
The effects of clouds on the diumal cycle of precipitation over the oceans have recently been studied by Randall et al. (1990). They analyzed simulations with the CSU GCM that show, in agreement with observations, a tendency for an early morning precipitation maximum over the tropical oceans far from land. To eliminate the remote effects of the continents as a possible cause of this oscillation, they performed "Seaworld" experiments, and obtained essentially the same results as in the Earth simulations. Fig. 6 shows the precipitation as a function of latitude and local time of day, for both Seaworid and an experiment in which Seaworld was assumed to be cloudfree. Although both runs show a morning maximum, the amplitude is much stronger in the run with clouds.

Further simulations with a one-dimensional version of the GCM, in which the large-scale vertical motion can be prescribed, showed that the morning maximum is not due to diurnal variations of the large-scale vertical motion, but is caused by radiative forcing associated with the clouds.

In brief, the mechanism is as follows. Large-scale lifting and surface cvaporation provide "background" destabilizing influences that tend to promote convection. Convection rains out moisture and warms the troposphere relative to the sea surface, thus providing a stabilizing negative feedback. Radiative effects modulate this balance between large-scale destabilization and convective stabilization. Longwave cooling tends to destabilize, while solar warming tends to stabilize. During the afternoon, the net rate of non-convective destabilization is tends to be minimized by solar warming. This leads to an afternoon minimum in the precipitation rate. The absence of solar warming at night favors an early moming maximum in rainfall.

\section{Simulation of the seasonally varying CRF and comparison with observations}

The effects of clouds on the Earth's radiation budget have been qualitatively appreciated for many years, but only recently have satellite data revealed that the net effect of the clouds is to cool the Earth by about $20 \mathrm{~W} \mathrm{~m}^{-2}$. Some GCMs are able to reproduce the globally averaged planetary CRF fairly well (e.g., Cess and Potter, 1987; Harshvardhan et al., 1989).

As discussed by Schlesinger and Mitchell (1987), the existing coupled ocean-atmosphere GCMs give reasonably consistent predictions of the climate system's response to increasing $\mathrm{CO}_{2}$, so long as attention is focused on such globally averaged quantities as the surface air temperature and precipitation rate. They also agree that the $\mathrm{CO}_{2}$ induced warming of the surface air will be substantially stronger in high latitudes than near the equator, in part because of ice-albedo feedback, and in part because the relatively strong stratification at high latitudes prevents convective redistribution of surface warming to higher levels in the troposphere. Finally, they agree that the stratosphere will cool.

Here the agreement ends, however. When the results are examined in more detail, either by looking at regional distributions of climate change or by investigating the nesponse of a wider variety of climate state variables, major disagreements among the models rapidly come to light. For this reason current predictions of the magnitude, timing, and regional distribution of the climatic effects of increasing $\mathrm{CO}_{2}$ concentrations cannot be relied upon. Certainly they are not suitable for use by policy makers planning for the future of energy consumption, agriculture, or other critical human activities.

Recently, the GCM Intercomparison Project sponsored by the U. S. Department of Energy has taken an important step towards resolving this troubling uncertainty. The participants have conducted identical controlled, idealized climate-change experiments with about twenty 
atmospheric GCMs. Each group has carried out three perpetual-July simulations. The first used observed climatological sea surface temperatures (SSTs), the second used SSTs increased to $2 \mathrm{~K}$ above climatology everywhere, and the third used SSTs reduced to $2 \mathrm{~K}$ below climatology everywhere. The group agreed upon a set of diagnostics to be saved in all simulations.

The results of these experiments have been reported by Cess et al. (1989; 1990). Briefly, they show that the gross climate sensitivities of the various models range over about a factor of thrie, but that virtually all of these differences can be accounted for by differences cloud eedbacks produced by the arious models.

Even before the GIP results were analyzed, many researchers had concluded that uncertainties about the effects of clouds are a key obstacle to reliable quantitative climate change predictions (e.g., Hansen et al., 1984). The important contribution of the GCM Intercomparison Project has been to quantitatively demonstrate this fact through systematic model intercomparisons.

It is difficult to devise a practical way to observationally test simulations of the changes in the cloudiness and the CRF that accompany climate changes. We cannot observe the clouds of a future climate until that future arrives; moreover, it seems very difficult to obtain reliable evidence of the cloud distributions characteristic of paleoclimates that we may attempt to simulate with our models.

A strategy designed to partially avoid this difficulty is to study the seasonal changes in the CRF. If a model cannot realistically simulate the changes in cloudiness and CRF that accompany seasonal change, it certainly cannot be trusted to realistically simulate cloud feedbacks on climate change. Seasonal changes are eminently observable. For this reason, seasonal change has long been used, by climate modelers, as a proxy for climate change.

Cess et al. (1990) have recently investigated the seasonal changes in the planetary CRF, as revealed by the ERBE data. We have reproduced their computations, and generated corresponding results from the UCLA / CSU GCM. Before presenting these results, it is necessary to introduce some definitions, following Cess et al. (1990). The forcing of the system due to the seasonal change of insolation, at any point on Earth, can be written as

$$
G=(1-\bar{\alpha}) \Delta S
$$

were $\alpha$ is the planetary albedo, $\mathbf{S}$ is the solar irradiance, an overbar denotes the annual mean, and $\Delta($ ) denotes a departure from the annual mean. The system responds by producing a change in the planetary albedo and the outgoing longwave radiation, $F$. This response can be written as

$$
R=S \Delta \alpha+\Delta F,
$$

where the first term represents the "short-wave response," and the second term represents the "longwave response." Let $R_{c}$ denote the response of the clear-sky fluxes, as observed by ERBE and/or as simulated by a GCM. Then we can define the seasonal response of the cloud radiative forcing as

$$
R_{c}-R=S\left(\Delta \alpha_{c}-\Delta \alpha\right)+\left(\Delta F_{c}-\Delta F\right)
$$


Note that the seasonal change of $\mathbf{S}$ does not appear in (3), because it is considered to be in the forcing, as expressed by (1). A more complete explanation of (3) is given by Cess et al. (1990). The first term of (3) can be called the "response of the shortwave CRF," and the second the "response of the longwave CRF."

We have evaluated the response of the shortwave CRF and the response of the longwave CRF using both ERBE data (Ramanathan et al., 1989) and simulations with the CSU GCM. Fig. 1 shows the results, for January. For January, the shortwave CRF response is negative in the northern middle latitudes, because of the seasonal increase in the cloud amount and the corresponding increase in the albedo. In the middle latitudes of the Southern Hemisphere, the shortwave CRF response is positive because of the seasonal decrease in cloudiness there. In the tropics, the January shortwave CRF response is positive north of the equator and negative south of the equator, because of the seasonal shift of the ITCZ toward the south.

The longwave CRF response for January (Fig. 2) is positive in the northem middle latitudes because of the seasonal increase in cloudiness and the associated increased trapping of terrestrial radiation; conversely, it is negative in the middle latitudes of the southern hemisphere. In the tropics, the longwave CRF response is negative north of the equator and positive south of the equator because of the seasonal shift of the ITCZ.

The GCM results are in remarkably close agneement with the observations.

Figs. 3 and 4 show the corresponding results for July. The observations can be interpreted more or less as before, with appropriate seasonal and latitudinal reversals. Again, the model results agree very well with the ERBE data.

This exercise illustrates how satellite data can be used to test the ability of a climate model to simulate the response of the CRF to extemal perturbations -- in this case, seasonal change. A dernonstration that the model can reproduce the observed seasonal changes fairly well increases our confidence in its ability to simulate the response of the CRF to other types of external perturbations, such as those associated with increasing $\mathrm{CO}_{2}$.

\section{Conclusions}

Twenty years ago the radiative effects of clouds on the atmospheric general circulation were almost completely unknown, but were widely believed to be negligible. Considerable research effort has been expended, over the past two decades, to correct this erroneous perception. It is now known that the atmospheric cloud radiative forcing is comparable in magnitude to the latent heating.

It was also believed, twenty years ago, that the poleward energy transports by the oceans are insignificant compared to those by the atmosphere. Numerous studies, based largely on satellite data, now strongly suggest that the energy transport by the oceans is comparable to that by the atmosphere.

During this same period, general circulation modeling of the atmosphere and, especially, the oceans has progressed to the point that coupled ocean-atmosphere GCMs are now being used in transient climate change simulations spanning decades and even centuries. It has long been recognized that realistic simulation of cloud radiative forcing is crucial for a successful coupled ocean-atmosphere model. We do not yet understand, however, how the coupled system responds to cloudiness perturbations, including those associated with model errors. Accurate measurements of the surface cloud radiative forcing will be essential to resolve this issue. 


\section{ACKNOWLEDGEMENTS}

I am grateful to my colleague Prof. Harshvardhan of Purdue University, without whom these cloud-radiation studies could not have been done. Donald Dazlich and WeiWei Jiang assisted with the numerical simulations.

Support has been provided by NASA's Climate Program under Grants NAG 5-1058 and NAG-1-893, and by the Department of Energy under Contract DCE-FG02-89ER69027. Computing support has been provided by the Numerical Aerodynamic Simulation Facility at NASA/Ames.

\section{REFERENCES}

Ackerman, T. P., K.-N. Liou, F. P. J. Valero, and L. Pfister, 1988. Heating rates in tropical anvils. J. Atmos. Sci. , 45, 1606-1623.

Albrecht, B., and S. K. Cox, 1975. The large-scale response of the tropical atmosphere to cloud modulated infrared heating. J. Atmos. Sci., 32: 16-24.

Cess, R. D., and G. L. Potter, 1987. Exploratory studies of cloud radiative forcing with a general circulation model. Tellus, 39A, 460-473

Cess, R. D., G. L. Potter, J. P. Blanchet, G. Boer, S. J. Ghan, J. T. Kiehl, X.-Z. Liang, J. F. B. Mitchell, J.-J. Morcrette, D. A. Randall, M. R. Riches, E. Roeckner, U. Schlese, A. Slingo, K. E. Taylor, W. M. Washington, R. T. Wetherald, and I. Yagai, 1989: Intercomparison and Interpretation of Cloud-Climate Feedback as Produced by Fourteen Atmospheric General Circulation Models. Science, 245, 513-516.

Cess, R. D., E. F. Harrison, P. Minnis, B. R. Barkstrom, V. Ramanathan, and T. Y Kwon, 1990: An interpretation of seasonal cloud-radiative forcing using Earth Radiation Budget Experiment data. In preparation.

Charlock, T. P., and V. Ramanathan, 1985. The albedo field and cloud radiative forcing produced by a general circulation model with internally generated cloud optics. J. Atmos. Sci., 42, 408-1429.

Ellis, J. S., 1978: Cloudiness, the planetary radiation budget, and climate. Ph.D. Thesis, Colorado State University, $129 \mathrm{pp}$.

Hansen, J., A. Lacis, D. Rind, G. Russell, P Stone, I, Fung, R. Ruedy, and J. Lerner, 1984. Climate sensitivity: Analysis of feedback mechanisms. Climate process and climate sensitivity, Maurice Ewing Series (5), J. E. Hansen and T. Takahashi, Eds., Amer. Geophys. Union: 130-163.

Harshvardhan, D. A. Randall, T. G. Corsetti, and D. A. Dazlich, 1989: Earth Radiation Budget and Cloudiness Simulations with a General Circulation Model. J. Atmos. Sci., 46, 19221942.

Ramanathan, V., E. J. Pitcher, R. C. Malone, and M. L. Blackmon, 1983. The response of a spectral general circulation model to refinements in radiative processes. J. Atmos. Sci., 40: $605-630$. 
Ramanathan, V., R. D. Cess, E. F. Harrison, P. Minnis, B. R. Barkstrom, E. Ahmad, and D. Hartmann, 1989: Cloud-radiative forcing and climate: Results from the Earth Radiation Budget Experiment. Science, 243, 57-63.

Randall, D. A., Harshvardhan, D. A. Dazlich, and T. G. Corsetti, 1989: Interactions Among Radiation, Convection, and Large-Scale Dynamics in a General Circulation Model. J. Atmos. Sci., 46, 1943-1970.

Randall, D. A., Harshvardhan, and D. A. Dazlich, 1990: Diurnal Variability of the Hydrologic Cycle in a General Circulation Model. Accepted for publication in the Journal of the Atmospheric Sciences.

Schlesinger, M. E. and J. F. B. Mitchell, 1987: Climate model simulations of the equilibrium climatic response to increased carbon dioxide. Rev. Geophys., 25 760.798.

Slingo, A., and J. M. Slingo, 1988: The response of a general circulation model to cloud longwave radiative forcing. I: Introduction and initial experiments. Quart. J. Roy. Meteor. Soc., 114, $1027-.1062$.

Stephens, G. L., and P. J. Webster, 1979: Sensitivity of radiative forcing to variable cloud and moisture. J. Atmos. Sci., 36, 1542-1556.

Webster, P. J., and G. L. Stephens, 1980. Tropical upper tropospheric extended clouds: Inferences from Winter MONEX. J. Atmos. Sci., 37, 1521-1541. 
Shortwave CRF Response for January, $\mathrm{W} \mathbf{m}^{\cdot 2}$
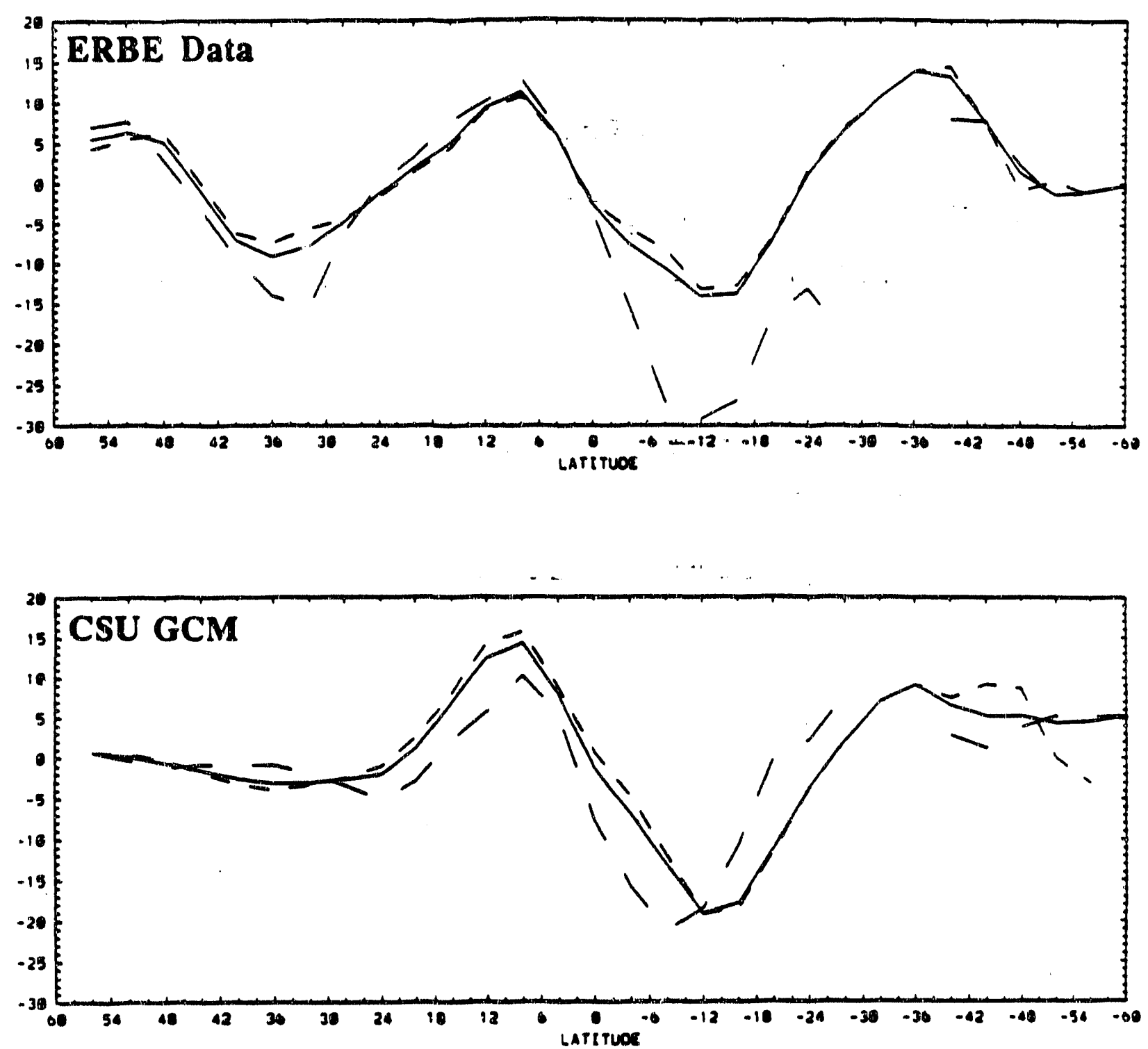

Figure 1 Seasonal response of the shortwave CRF, for January, as observed by ERBE (top panel) and as simulated by the CSU GCM (bottom panel). The solid line represents an average over all longitudes, the short dashed line an average over oceans only, and the long dashed line an average over land only. Data are presented from $60^{\circ} \mathrm{S}$ to $60^{\circ} \mathrm{N}$ only because of the difficulty in determining the high-latitude CRF from the ERBE data. 


\section{Longwave CRF Response for January, W m-2}
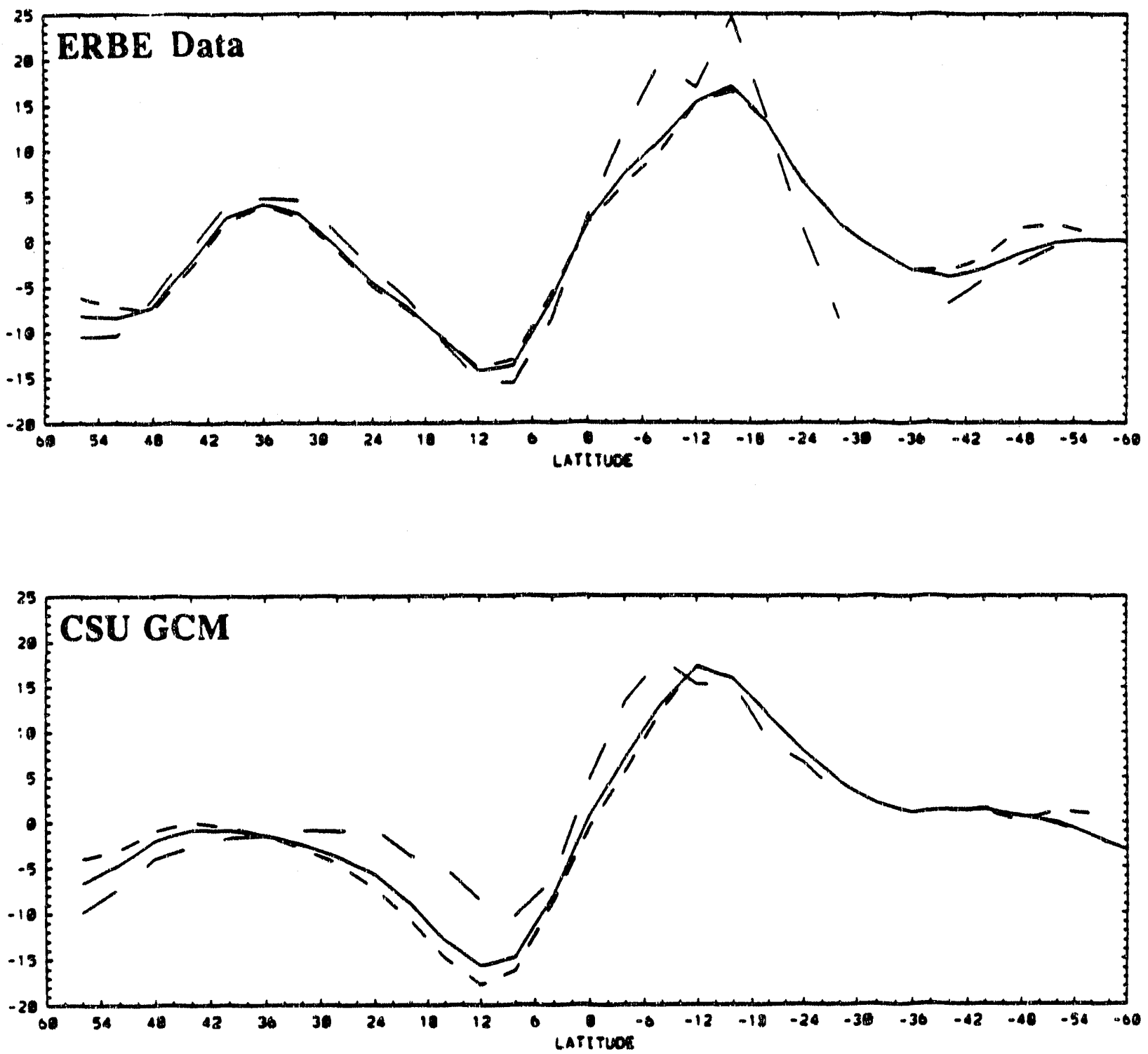

Figure 2 Seasonal response of the longwave CRF, for January, as observed by ERBE (top panel) and as simulated by the CSU GCM (bottom panel). The solid line represents an average over all longitudes, the short dashed line an average over oceans only, and the long dashed line an average over land only. Data are presented from $60^{\circ} \mathrm{S}$ to $60^{\circ} \mathrm{N}$ only because of the difficulty in determining the high-latitude CRF from the ERBE data. 


\section{Shortwave CRF Response for July, W $\mathbf{m}^{-2}$}
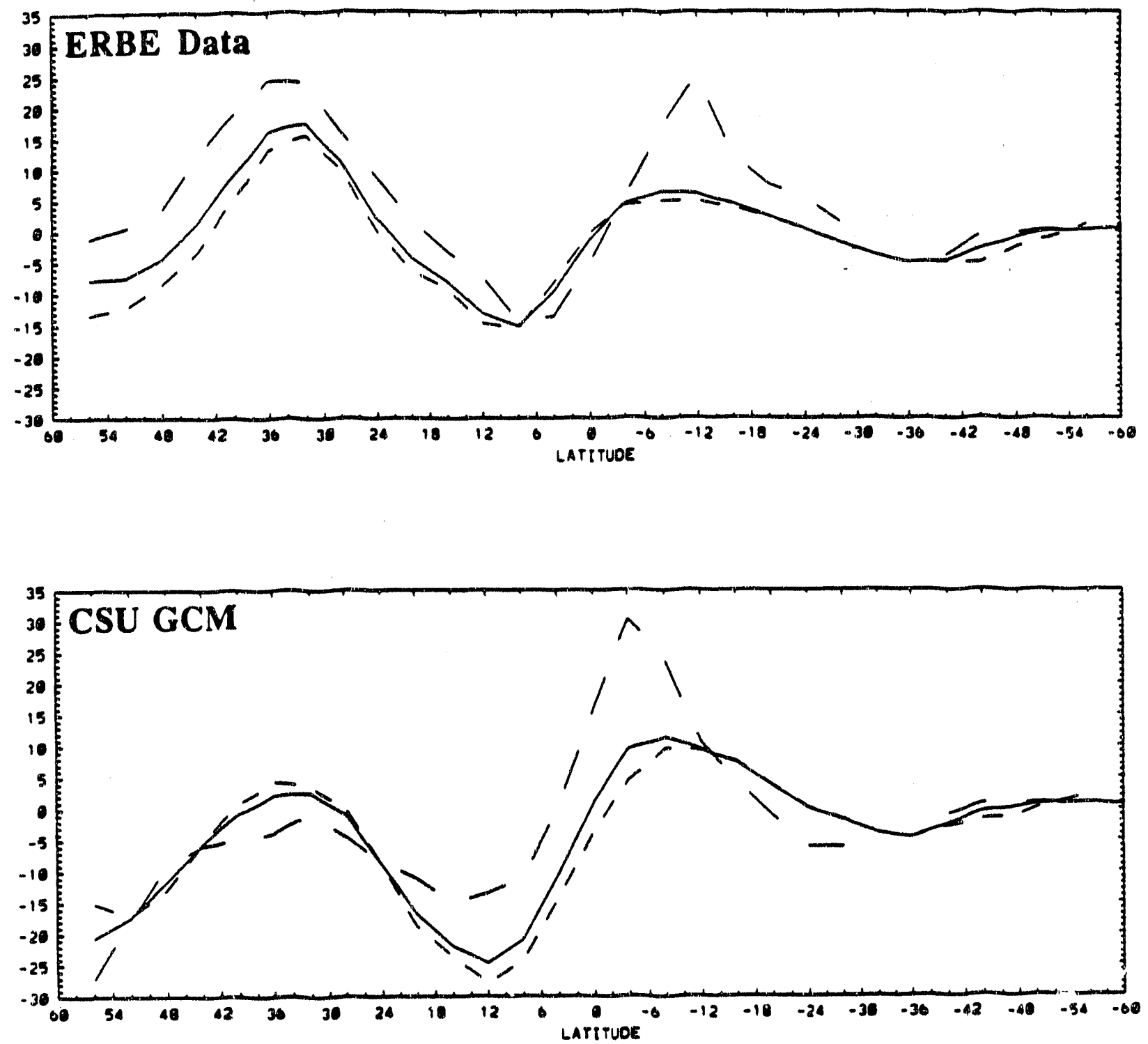

Figure 3 Seasonal response of the shortwave CRF, for July, as observed by ERBE (top panel) and as simulated by the CSU GCM (bottom panel). 'The solid line represents an average over all longitudes, the short dashed line an average over oceans only, and the long dashed line an average over land only. Data are presented from $60^{\circ} \mathrm{S}$ to $60^{\circ} \mathrm{N}$ only because of the difficulty in determining the high-latitude CRF from the ERBE data. 


\section{Longwave CRF Response for July, W $\mathbf{m}^{-2}$}
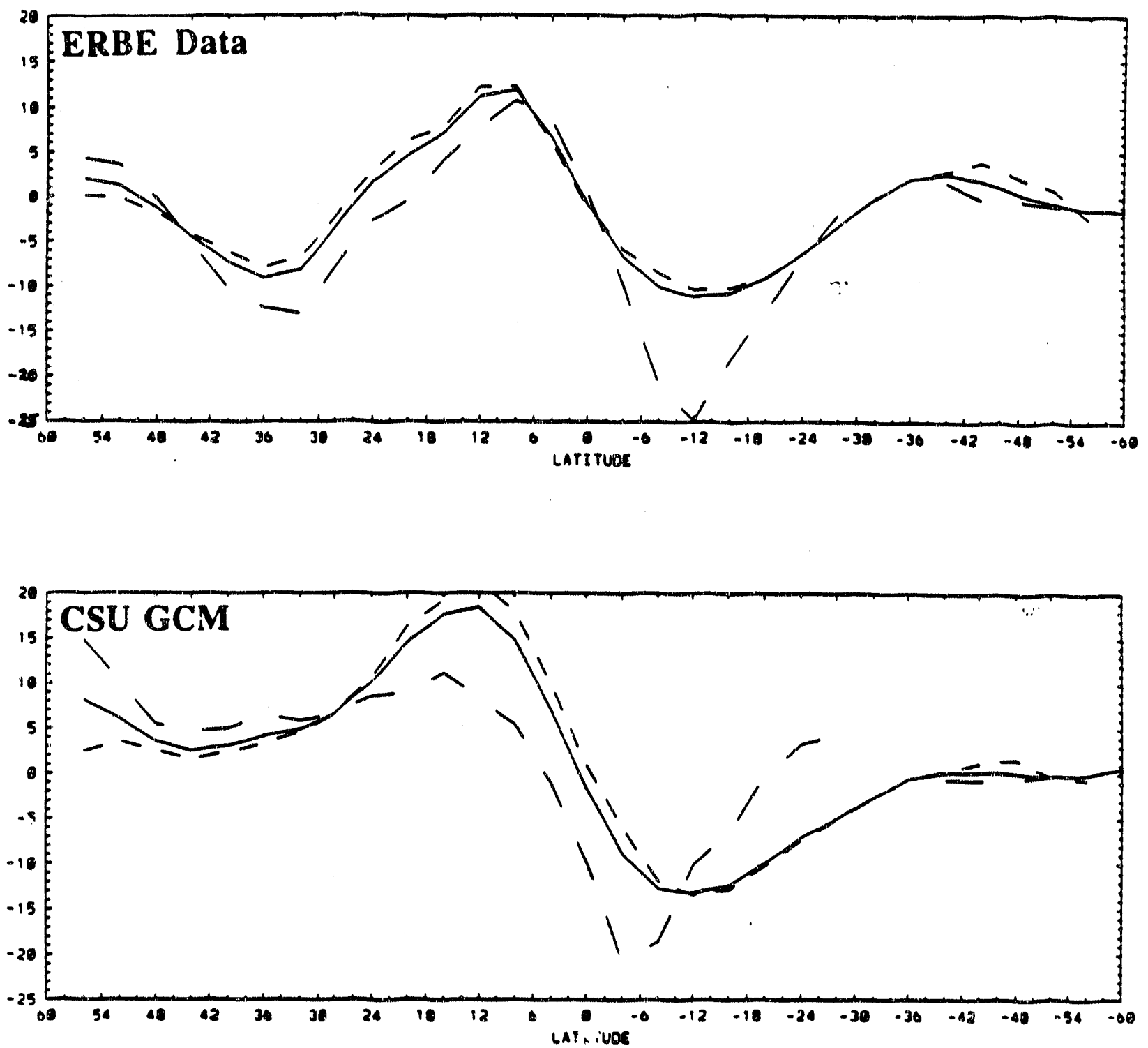

Figure 4 Seasonal response of the longwave CRF, for July, as observed by ERBE (top panel) and as simulated by the CSU GCM (bottom panel). The solid line represents an average over all longitudes, the short dashed line an average over oceans only, and the long dashed line an average over land only. Data are presented from $60^{\circ} \mathrm{S}$ to $60^{\circ} \mathrm{N}$ only because of the difficulty in determining the high-latitude CRF from the ERBE data. 

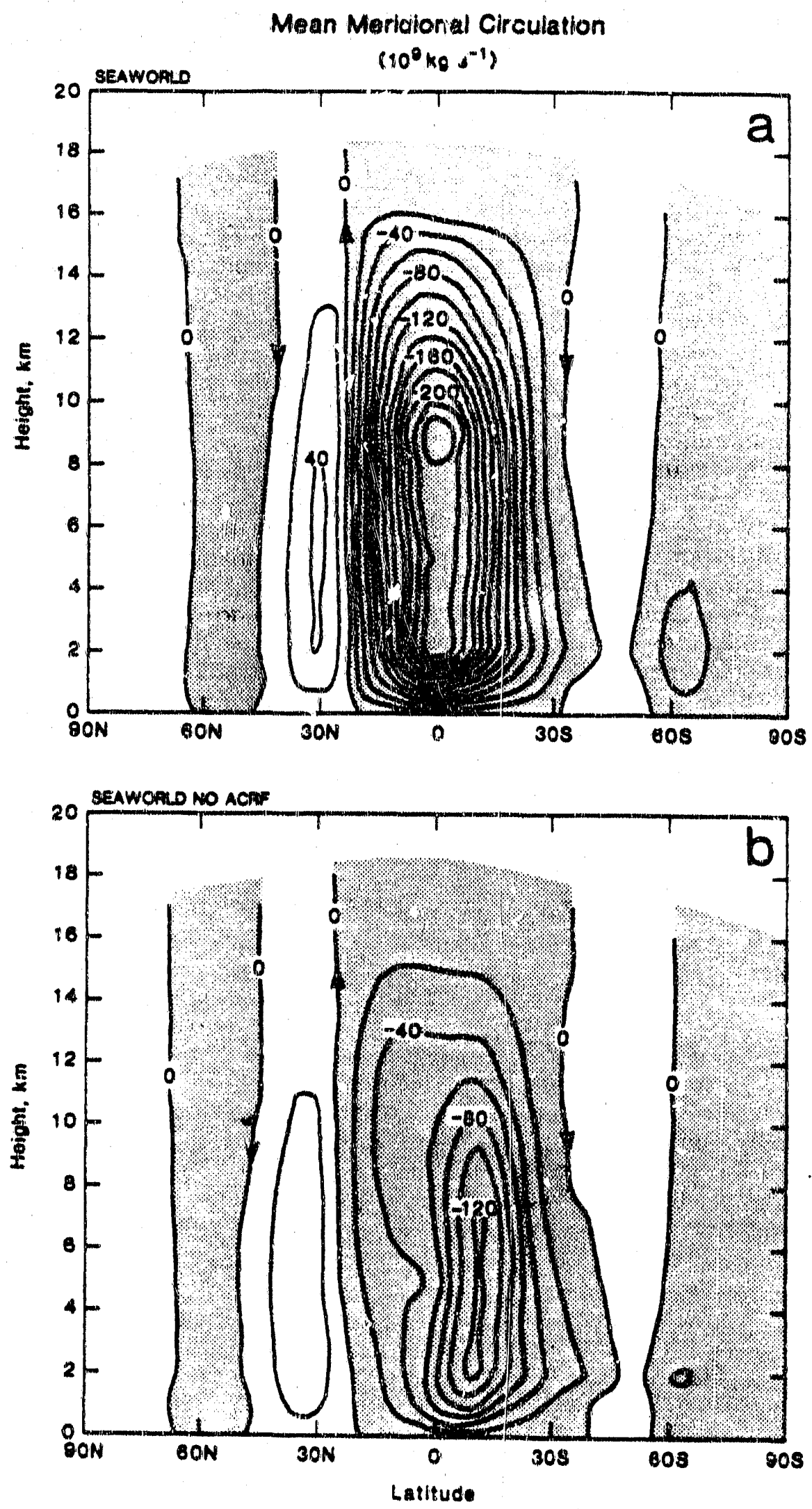

Figure 5 Simulated mean meridional circulation for Seaworld "with the radiative effects of clouds (top panel) and without (bottorn panel). The units are billionst of lélograms per second. 
Daily Variations of

Precipitation on Seaworld, $\mathrm{mm}$ doy ${ }^{-1}$
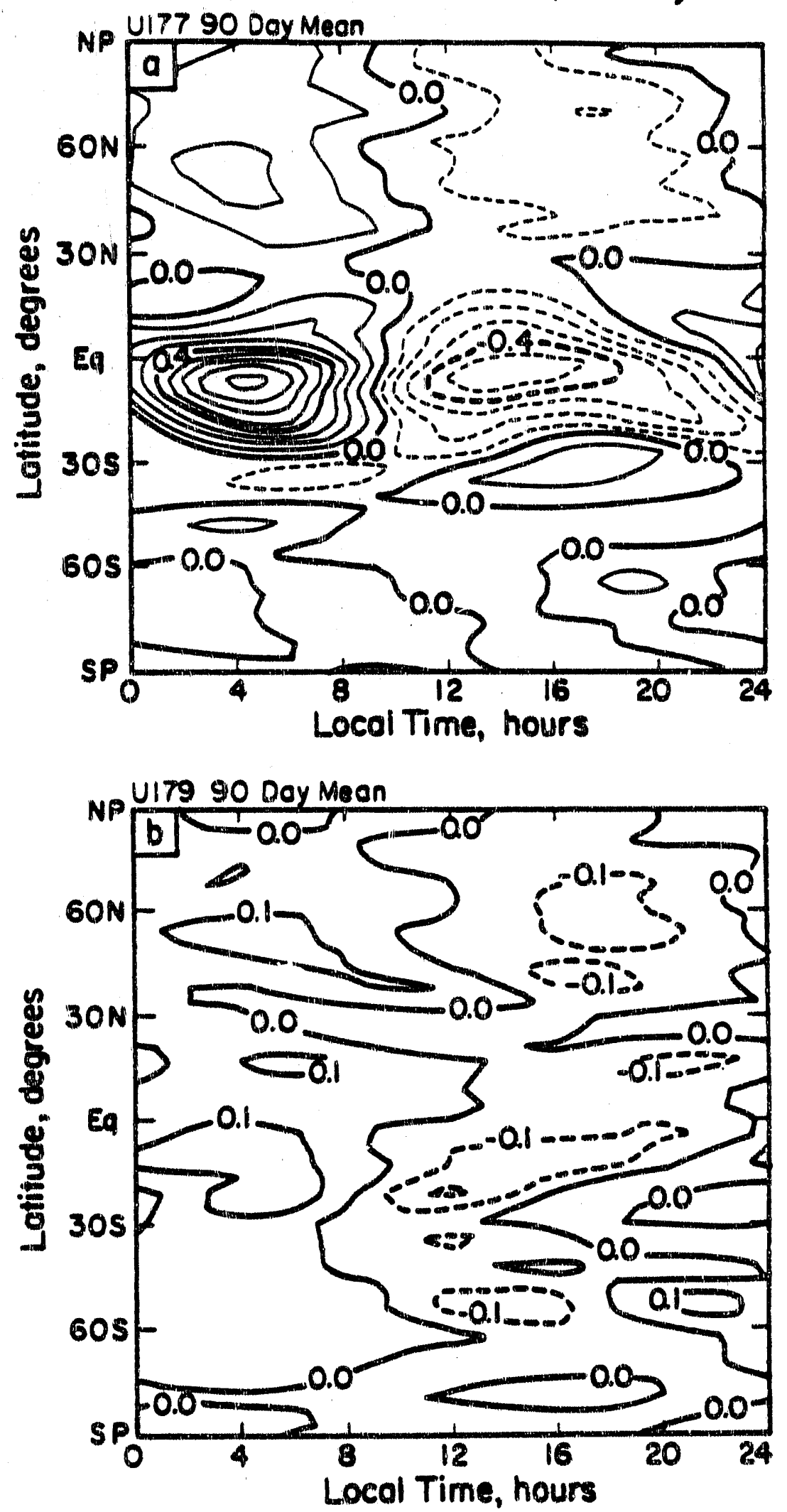

Figure 6 The simulated precipitation for the a) cloudy, and b) cloud-free Seaworld simulations, plotted as a function of latitude and local time, including only the contributions from the first two diumal harmonics. The units are mm day'- 

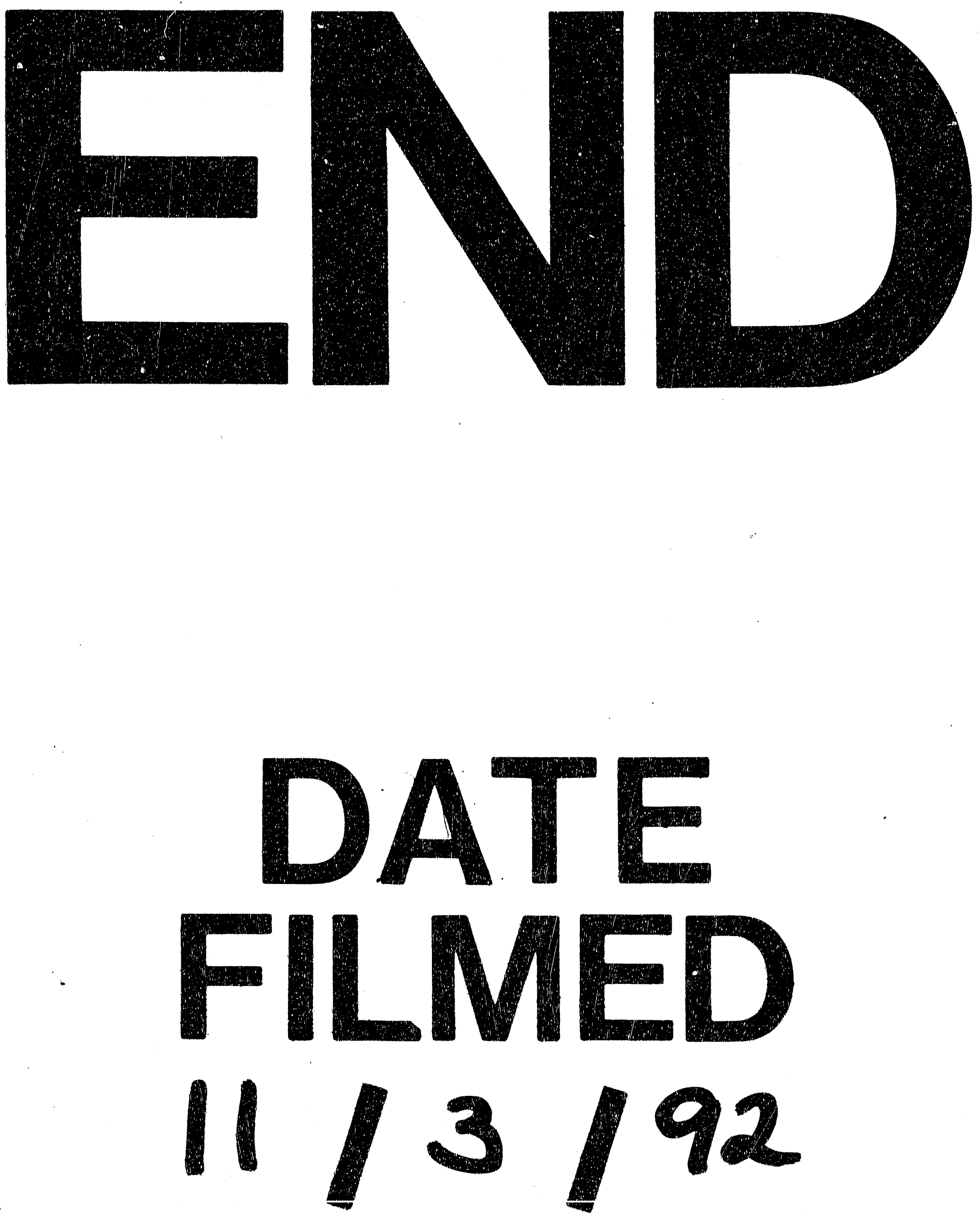

疌 
